Pacific Journal of Mathematics

COMMON FIXED POINTS AND ITERATION OF COMMUTING 


\title{
COMMON FIXED POINTS AND ITERATION OF COMMUTING NONEXPANSIVE MAPPINGS
}

\author{
SHIRO ISHIKAWA
}

The following result is shown. Let $T_{i}(i=1,2, \cdots, \nu)$ be commuting nonexpansive self-mappings on a compact convex subset $D$ of a Banach space and let $x$ be any point in $D$. Then the sequence

$$
\left\{\left[\prod_{n_{\nu}-1=1}^{n_{\nu}}\left[S_{\nu} \prod_{n_{\nu}-2=1}^{n_{\nu}-1}\left[\cdots\left[S_{3} \prod_{n_{1}=1}^{n_{2}}\left[S_{2} \prod_{n_{0}=1}^{n_{1}} S_{1}\right]\right] \cdots\right]\right] x\right\}_{n_{\nu=1}}^{\infty}\right.
$$

converges to a common fixed point of $\{T\}_{i=1}^{\nu}$, where $S_{i}=$ $\left(1-\alpha_{i}\right) I+\alpha_{i} T_{i}, 0<\alpha_{i}<1, I$ is the identity mapping.

In [2], DeMarr proved that if $T_{i}(i \in J, J$ is an index set) are commuting nonexpansive self-mappings on a compact convex subset $D$ of a Banach space (i.e., $\|T x-T y\| \leqq\|x-y\|$ for all $x, y$ in $D$, and $T_{i} T_{j}=T_{j} T_{i}$ for all $\left.i, j \in J\right)$, then $T_{i}(i \in J)$ have a common fixed point in $D$.

The problem we shall consider in this paper is that of constructing a sequence of points $\left\{x_{n}\right\}_{n=1}^{\infty}$ in $D$ that converges to the common fixed point of $T_{i}(i \in J, J$ is a finite index set).

If a Banach space is strictly convex (i.e., $\|\alpha x+(1-\alpha) y\|<$ $\max \{\|x\|,\|y\|\}$ for $x \neq y, 0<\alpha<1$ ), the problem was solved in [5].

Throughout this paper, we denote an identity mapping by $I$ and the set of fixed points of $T$ by $F[T]$. And we define $\prod_{i=1}^{n+1} T_{i}=$ $T_{n+1}\left(\prod_{i=1}^{n} T_{i}\right)$ for any positive integer $n$ and $\prod_{i=1}^{1} T_{i}=T_{1}$.

We have the following main theorem.

Theorem. Let $T_{i}(i=1,2, \cdots \nu)$ be commuting nonexpansive mappings from a compact convex subset $D$ of a Banach space into itself, and let $x$ be any point in $D$.

Then $\bigcap_{i=1}^{\nu} F\left[T_{i}\right]$ is nonempty and the sequence $\left\{x_{n_{\nu}}^{\infty}\right\}$ converges to a point in $\bigcap_{i=1}^{\nu} F\left[T_{i}\right]$, where $x_{n_{\nu}}$ is defined for each positive integer $n_{t} b y$

$$
\left[\prod_{\mathfrak{l}-1=1}^{n_{\mathfrak{l}}}\left[S_{\mathfrak{l}} \prod_{n_{\mathfrak{l}-2}=1}^{n_{\mathfrak{l}}-1}\left[S_{\mathfrak{l}-1} \cdots\left[S_{3} \prod_{n_{1}=1}^{n_{2}}\left[S_{2} \prod_{n_{0}=1}^{n_{1}} S_{1}\right]\right] \cdots\right]\right] x\right.
$$

where $S_{i}=\left(1-\alpha_{i}\right) I+\alpha_{i} T_{i}, 0<\alpha_{i}<1(i=1,2, \cdots, \nu)$.

Before proving the theorem, we first prove the following lemmas on which the proof of theorem is based.

Lemma 1. Let $T$ and $P$ be nonexpansive mappings from a 
bounded convex subset $D$ of a Banach space into itself that satisfy the conditions

$$
P(D)=F[P] \quad \text { and } \quad T(P(D)) \subset P(D) .
$$

Let $x_{0}$ be any point in $D$ and let $\alpha$ be any number such that $0<\alpha<1$. Then the sequences $\left\{x_{n}-T x_{n}\right\}_{n=0}^{\infty}$ and $\left\{x_{n}-P x_{n}\right\}_{n=0}^{\infty}$ respectively converge to zero, where $x_{n}$ is defined for each positive integer $n$ by

$$
x_{n}=(1-\alpha) y_{n}+\alpha T y_{n}, \quad y_{n}=P x_{n-1},
$$

that, is $x_{n}=(S P)^{n} x_{0}$, where $S=(1-\alpha) I+\alpha T$.

Proof. We see from (1) that for all $n \geqq 1$

$$
y_{n}=P y_{n} \quad \text { and } \quad T y_{n}=P T y_{n} .
$$

Since $T$ and $P$ are nonexpansive mappings, we have, from (2) and (3), for all $n \geqq 0$

$$
\left\|y_{n+1}-T y_{n+1}\right\|=\left\|P x_{n}-P T y_{n+1}\right\| \leqq\left\|x_{n}-T y_{n+1}\right\|
$$

and, from (2) and (3), for all $n \geqq 1$

$$
\begin{aligned}
\left\|x_{n}-T y_{n+1}\right\| & \leqq\left\|x_{n}-T y_{n}\right\|+\left\|T y_{n}-T y_{n+1}\right\| \\
& \leqq(1-\alpha)\left\|y-T y_{n}\right\|+\left\|y_{n}-y_{n+1}\right\| \\
& \leqq(1-\alpha)\left\|y_{n}-T y_{n}\right\|+\left\|P y_{n}-P x_{n}\right\| \\
& \leqq(1-\alpha)\left\|y_{n}-T y_{n}\right\|+\left\|y_{n}-x_{n}\right\| \\
& \leqq(1-\alpha)\left\|y_{n}-T y_{n}\right\|+\alpha\left\|y_{n}-T y_{n}\right\|=\left\|y_{n}-T y_{n}\right\|
\end{aligned}
$$

from which, we obtain

$$
\left\|y_{n+1}-T y_{n+1}\right\| \leqq\left\|x_{n}-T y_{n+1}\right\| \leqq\left\|y_{n}-T y_{n}\right\| \text { for all } n \geqq 1
$$

Hence the sequence $\left\{\left\|y_{n}-T y_{n}\right\|_{n=1}^{\infty}\right.$, which is nonincreasing and bounded below, has a limit.

Suppose that $\lim \left\|y_{n}-T y_{n}\right\|=r>0$, that is, for any $\varepsilon>0$, there is an integer $m$ such that

$$
r \leqq\left\|y_{n}-T y_{n}\right\| \leqq(1+\varepsilon) r \quad \text { for all } n \geqq m \text {. }
$$

Also, from the boundedness of $D$, we can choose $M$ such that

(5) $\quad L \leqq(M-m) r<2 L$, where $L$ is a diameter of $D$.

We have from (3), (2) and (4) that for any $n \geqq m$ and $k \geqq 0$

$$
\begin{aligned}
\left\|y_{n}-y_{n+k+1}\right\| & \leqq\left\|y_{n}-y_{n+1}\right\|+\left\|y_{n+1}-y_{n+2}\right\|+\cdots+\left\|y_{n+k}-y_{n+k+1}\right\| \\
& \leqq\left\|P y_{n}-P x_{n}\right\|+\left\|P y_{n+1}-P x_{n+1}\right\|+\cdots+\left\|P y_{n+k}-P x_{n+k}\right\| \\
& \leqq\left\|y_{n}-x_{n}\right\|+\left\|y_{n+1}-x_{n+1}\right\|+\cdots+\left\|y_{n+k}-x_{n+k}\right\|
\end{aligned}
$$




$$
\leqq \alpha(k+1)(1+\varepsilon) r .
$$

Now we shall prove by induction that

$$
(1+\alpha k)(1+\varepsilon) r-(1-\alpha)^{-k} \varepsilon r \leqq\left\|T y_{M}-y_{M-k}\right\|
$$

for any $k$ such that $0 \leqq k \leqq M-m$.

When $k=0$, the result is trivial. Now we assume that (7) is true for some $k$ such that $0 \leqq k \leqq M-m-1$. We see, from (3) and (2), that

$$
\begin{aligned}
\left\|T y_{M}-y_{M-k}\right\| & =\left\|P T y_{M}-P x_{M-(k+1)}\right\| \leqq\left\|T y_{M}-x_{M-(k+1)}\right\| \\
& =\left\|(1-\alpha)\left(T y_{M}-y_{M-(k+1)}\right)+\alpha\left(T y_{M}-T y_{M-(k+1)}\right)\right\| \\
& \leqq(1-\alpha)\left\|T y_{M}-y_{M-(k+1)}\right\|+\alpha\left\|y_{M}-y_{M-(k+1)}\right\|
\end{aligned}
$$

from which and (6), it follows that

$$
\left\|T y_{M}-y_{M-k}\right\| \leqq(1-\alpha)\left\|T y_{M}-y_{M-(k+1)}\right\|+\alpha^{2}(k+1)(1+\varepsilon) r .
$$

From this and the assumption by induction, we have

$$
\begin{aligned}
& (1+\alpha k)(1+\varepsilon) r-(1-\alpha)^{-k} \varepsilon r \\
& \quad \leqq(1-\alpha)\left\|T y_{M}-y_{M-(k+1)}\right\|+\alpha^{2}(k+1)(1+\varepsilon) r
\end{aligned}
$$

and it is clear that this inequality is equal to (7) with $k+1$ for $k$. Hence, by induction, it follows that (7) is true for any $k$ such that $0 \leqq k \leqq M-m$.

Since $\log (1+t) \leqq t$ for all $t \in(-1, \infty)$, we have from (5) that

$$
\begin{aligned}
(1-\alpha)^{-(M-m)} & =\exp \left[(M-m) \log \left(1+\frac{\alpha}{1-\alpha}\right)\right] \\
& \leqq \exp \left[(M-m) \frac{\alpha}{1-\alpha}\right] \leqq \exp \left(\frac{2 L}{(1-\alpha) r}\right)
\end{aligned}
$$

Thus it follows from (7) with $M-m$ for $k$ that

$$
\begin{aligned}
\left\|T y_{M}-y_{m}\right\| & \geqq(1+\alpha(M-m))(1+\varepsilon) r-\varepsilon r \exp \left(\frac{2 L}{(1-\alpha) r}\right) \\
& \geqq(r+L)-\varepsilon r \exp \left(\frac{2 L}{(1-\alpha) r}\right) .
\end{aligned}
$$

Since $\varepsilon$ is any positive number, this inequality is imcompatible with the definition of $L$. Hence we obtain that $r=0$, that is,

$$
\lim _{n \rightarrow \infty}\left\|y_{n}-T y_{n}\right\|=0 \text {. }
$$

Now since $T$ and $P$ are nonexpansive mappings, we have from (2) and (3) that, for all $n \geqq 1$, 


$$
\begin{aligned}
\left\|x_{n}-T x_{n}\right\| & =\left\|(1+\alpha) y_{n}+\alpha T y_{n}-T\left((1-\alpha) y_{n}+\alpha T y_{n}\right)\right\| \\
& =\left\|(1-\alpha) y_{n}-(1-\alpha) T y_{n}+T y_{n}-T\left((1-\alpha) y_{n}+\alpha T y_{n}\right)\right\| \\
& \leqq(1-\alpha)\left\|y_{n}-T y_{n}\right\|+\alpha\left\|y_{n}-T y_{n}\right\| \\
& =\left\|y_{n}-T y_{n}\right\|
\end{aligned}
$$

and

$$
\begin{aligned}
\left\|x_{n}-P x_{n}\right\|= & \left\|(1-\alpha) y_{n}+\alpha T y_{n}-P\left((1-\alpha) y_{n}+\alpha T y_{n}\right)\right\| \\
= & \|(1-\alpha)\left[P y_{n}-P\left((1-\alpha) y_{n}+\alpha T y_{n}\right)\right] \\
& +\alpha\left[P T y_{n}-P\left((1-\alpha) y_{n}+\alpha T y_{n}\right)\right] \| \\
\leqq & 2 \alpha(1-\alpha)\left\|y_{n}-T y_{n}\right\| .
\end{aligned}
$$

Therefore we obtain that from (8) that

$$
\lim _{n \rightarrow \infty}\left\|x_{n}-T x_{n}\right\|=\lim _{n \rightarrow \infty}\left\|x_{n}-P x_{n}\right\|=0 \text {. }
$$

Lemma 2. Let $T$ and $P$ be nonexpansive mappings from $a$ compact convex subset $D$ of a Banach space into itself such that

$$
P(D)=F[P] \text { and } T(P(D)) \subset P(D) .
$$

Let $x_{0}$ be any point in $D$. Define $x_{n}=\bar{P}_{n} x_{0}$ for each positive integer $n$, where $\bar{P}_{n}=(S P)^{n}, S=(1-\alpha) I+\alpha T, 0<\alpha<1$. Then it follows that

(10) for any $x_{0}$ in $D, \lim _{n \rightarrow \infty}(S P)^{n} x_{0}=P x_{0}$ exists, which is, denoted by $\bar{P} x_{0}$,

$$
\bar{P}(D)=F[\bar{P}]=F[T] \cap F[P]
$$

and

$$
\left\{\bar{P}_{n}\right\}_{n=1}^{\infty} \text { converges uniformly to } \bar{P} \text {. }
$$

Proof. Since $D$ is compact, there exists a subsequence $\left\{x_{n_{i}}\right\}_{i=1}^{\infty}$ of $\left\{x_{n}\right\}$ that converges to a point $u$ in $D$. From the boundedness of $D$, Lemma 1 is applicable, so we have,

$$
\begin{aligned}
\|u-T u\| & \leqq \lim _{i \rightarrow \infty}\left\{\left\|u-x_{n_{i}}\right\|+\left\|x_{n_{i}}-T x_{n_{i}}\right\|+\left\|T x_{n_{i}}-T u\right\|\right\} \\
& \leqq \lim _{i \rightarrow \infty}\left\{2\left\|x_{n_{i}}-n\right\|+\left\|x_{n_{i}}-T x_{n_{i}}\right\|\right\}=0
\end{aligned}
$$

and similarly $\|u-P u\|=0$.

From this, it follows that

$$
u \in F[T] \cap F[P] .
$$

Since (9) implies (3), we see from (13) and (3) that for all $n \geqq 0$, 


$$
\begin{aligned}
\left\|u-x_{n+1}\right\| & =\left\|u-\left((1-\alpha) y_{n+1}+\alpha T y_{n+1}\right)\right\| \\
& \leqq(1-\alpha)\left\|u-y_{n+1}\right\|+\alpha\left\|T u-T y_{n+1}\right\| \\
& \leqq\left\|u-y_{n+1}\right\|=\left\|P u-P x_{n}\right\| \leqq\left\|u-x_{n}\right\| .
\end{aligned}
$$

From this, we obtain that $\lim _{n \rightarrow \infty}\left\|u-x_{n}\right\|=\lim _{n_{i} \rightarrow \infty}\left\|u-x_{n_{i}}\right\|=0$. Hence we have proved that (10) is true, that is, for any $x_{0}$ in $D, \bar{P}\left(x_{0}\right)=$ $\lim _{n \rightarrow \infty}(S P)^{n} x_{0}$ is well-defined. From (13), we see that $\bar{P}\left(x_{0}\right) \in F[T] \cap F[P]$ for all $x_{0}$ in $D$, that is,

$$
\bar{P}(D) \subset F(T) \cap F[P] \text {. }
$$

And we have that, for any $v$ in $F[T] \cap F[P]$,

$$
v=(S P)^{n} v=\lim _{n \rightarrow \infty}(S P)^{n} v=\bar{P} v,
$$

so we see that

$$
F[T] \cap F[P] \subset F[\bar{P}] \text {. }
$$

Also, clearly $w=\bar{P} w \in \bar{P}(D)$ for all $w$ in $F[\bar{P}]$. From this, (14) and (15), we get (11).

Finally we shall prove (12). Let $\varepsilon$ be any positive number. Since $D$ is compact, there are finite points $\left\{x_{0}^{1}, x_{0}^{2}, \cdots, x_{0}^{k}\right\}$ such that, for any $x$ in $D$,

$$
\min \left\{\left\|x-x_{0}^{i}\right\|: 1 \leqq i \leqq k\right\}<\frac{\varepsilon}{3} .
$$

From (10), we can choose $N$ such that

$$
\left\|(S P)^{n} x_{0}^{i}-\bar{P} x_{0}^{i}\right\|<\frac{\varepsilon}{3} \quad \text { for all } n \geqq N \text { and } \quad 1 \leqq i \leqq k .
$$

Let $x_{0}$ be any point in $D$. From (16), we can take $x_{0}^{j}$ such that

$$
\left\|x_{0}-x_{0}^{j}\right\|<\frac{\varepsilon}{3}
$$

Since $S P$ is nonexpansive, clearly $\bar{P}$ is also nonexpansive. Hence we obtain from (17) and (18) that, for all $n \geqq N$,

$$
\begin{aligned}
& \left\|(S P)^{n} x_{0}-\bar{P} x_{0}\right\| \\
& \quad \leqq\left\|(S P)^{n} x_{0}-(S P)^{n} x_{0}^{j}\right\|+\left\|(S P)^{n} x_{0}^{j}-\bar{P} x_{0}^{j}\right\|+\left\|\bar{P} x_{0}^{j}-\bar{P} x_{0}\right\| \\
& \quad \leqq 2\left\|x_{0}-x_{0}^{j}\right\|+\left\|(S P)^{n} x_{0}^{j}-\bar{P} x_{0}^{j}\right\| \leqq \varepsilon
\end{aligned}
$$

which implies (12).

Lemma 3. Let $T$ and $P_{n}(n=1,2, \cdots)$ be nonexpansive mappings from a compact convex subset $D$ of a Banach space into itself. Assume 
that the following conditions are satisfied:

$$
\begin{gathered}
\text { for any } x \text { in } D, \lim _{n \rightarrow \infty} P_{n} x=P x \text { exists }, \\
P(D)=F[P] \subset F\left[P_{n}\right] \quad \text { for all } n \geqq 1 \\
P_{n} \text { converges uniformly to } P
\end{gathered}
$$

and

$$
T(P(D)) \subset P(D)
$$

Then it follows that

(23) for any $x$ in $D, \lim _{n \rightarrow \infty} \hat{P}_{n} x=\hat{P} x$ exists, where $\hat{P}_{n}=\prod_{i=1}^{n}\left(S P_{i}\right)$, $S=(1-\alpha) I+\alpha T, 0<\alpha<1$,

$$
\hat{P}(D)=F[\hat{P}]=F[T] \cap F[P] \subset F\left[\hat{P}_{n}\right] \quad \text { for all } n \geqq 1
$$

and

$$
\hat{P}_{n} \text { converges uniformly to } \hat{P} \text {. }
$$

Proof. Let $\varepsilon$ be any positive number. Since $P$ satisfies the conditions of $P$ in Lemma 2, from (12), we can choose $N$ such that

$$
\left\|(S P)^{N} y-\bar{P} y\right\|<\frac{\varepsilon}{2} \quad \text { for all } y \text { in } D,
$$

where $\bar{P}$ is defined as in Lemma 2 .

From (21), there exists $M$ such that

$$
\left\|S P x-S P_{n} x\right\| \leqq\left\|P x-P_{n} x\right\| \leqq \frac{\varepsilon}{2 N}
$$

for all $n \geqq M$ and all $x$ in $D$.

This implies that, for all $n$ such that $n \geqq M$

$$
\begin{aligned}
& \left\|\hat{P}_{n} x-(S P)^{N} \hat{P}_{n-N} x\right\| \\
& \quad \leqq\left\|\left(S P_{n}\right) \hat{P}_{n-1} x-(S P) \hat{P}_{n-1} x\right\|+\left\|(S P) \hat{P}_{n-1} x-(S P)(S)^{N-1} \hat{P}_{n-N} x\right\| \\
& \quad \leqq \frac{\varepsilon}{2 N}+\left\|\hat{P}_{n-1} x-(S P)^{N-1} \hat{P}_{n-N} x\right\| \\
& \quad \leqq 2 \frac{\varepsilon}{2 N}+\left\|\hat{P}_{n-2} x-(S P)^{N-2} \hat{P}_{n-N} x\right\| \leqq \cdots \leqq \frac{\varepsilon}{2} .
\end{aligned}
$$

From this and (26), we have that, for all $n$ such that $n \geqq \max \{N, M\}$,

$$
\begin{aligned}
\left\|\hat{P}_{n} x-\bar{P}\left(\hat{P}_{n-N} x\right)\right\| & \leqq\left\|\hat{P}_{n} x-(S P)^{N} \hat{P}_{n-N} x\right\|+\left\|(S P)^{N} \hat{P}_{n-N} x-\bar{P}\left(\hat{P}_{n-N} x\right)\right\| \\
& \leqq \varepsilon .
\end{aligned}
$$


Since Lemma 2 says that $\bar{P}(D)=F[T] \cap F[P]$, this implies that there exists a subsequence $\left\{\hat{P}_{n_{i}} x\right\}_{i=1}^{\infty}$ that converges to a point $u$ in $F[T] \cap$ $F[P]$. Also we see, from (20), for all $n \geqq 1$,

$$
\left\|\hat{P}_{n+1} x-u\right\|=\left\|S P_{n+1} \hat{P}_{n} x-S P_{n+1} u\right\| \leqq\left\|\hat{P}_{n} x-u\right\| \text {. }
$$

Hence we get that $\lim _{n \rightarrow \infty}\left\|\hat{P}_{n} x-u\right\|=\lim _{i \rightarrow \infty}\left\|\hat{P}_{n_{i}} x-u\right\|=0$, that is, $\hat{P}_{n} x$ converges to a point in $F[T] \cap F[P]$ for any $x$ in $D$. This implies (23), and

$$
\hat{P}(D) \subset F[T] \cap F[P] \text {. }
$$

If $v \in F[T] \cap F[P]$, then $v=\hat{P}_{n} v=\lim _{n \rightarrow \infty} \hat{P}_{n} v=\hat{P} v$, so we see

$$
F[T] \cap F[P] \subset F[\hat{P}] \text {. }
$$

Since clearly $F[\hat{P}] \subset \hat{P}(D)$ and $F[T] \cap F[P] \subset F\left[\hat{P}_{n}\right]$ for all $n \geqq 1$, (24) follows from (27) and (28).

Now we shall prove (25). Let $\varepsilon$ be any positive number. As in the proof of Lemma 2 , we can choose finite points $\left\{x_{0}^{1}, x_{0}^{2}, \cdots, x_{0}^{k}\right\}$ from $D$ satisfying (16). From (23), we can choose $N^{\prime}$ such that

$$
\left\|\hat{P}_{n} x_{0}^{i}-\hat{P} x_{0}^{i}\right\| \leqq \frac{\varepsilon}{3} \quad \text { for all } n \geqq N^{\prime} \text { and } 1 \leqq i \leqq k .
$$

Let $x_{0}$ be any point in $D$. By (16), we can take $x_{0}^{j}$ that satisfies (18). Since $\hat{P}$ is nonexpansive, we obtain from (18) and (29) that, for all $n \geqq N^{\prime}$,

$$
\begin{aligned}
& \left\|\hat{P}_{n} x_{0}-\hat{P} x_{0}\right\| \\
& \quad \leqq\left\|\hat{P}_{n} x_{0}-\hat{P}_{n} x_{0}^{j}\right\|+\left\|\hat{P}_{n} x_{0}^{j}-\hat{P} x_{0}^{j}\right\|+\left\|\hat{P} x_{0}^{j}-\hat{P} x_{0}\right\| \\
& \quad \leqq 2\left\|x_{0}-x_{0}^{j}\right\|+\left\|\hat{P}_{n} x_{0}^{j}-\hat{P} x_{0}^{j}\right\| \leqq \varepsilon .
\end{aligned}
$$

This implies (25).

Lemma 4. Let $T_{i}(i=1,2, \cdots, k)$ be a commuting family of mappings. Then it follows that

$$
T_{k}\left(\bigcap_{i=1}^{k-1} F\left[T_{i}\right]\right) \subset \bigcap_{i=1}^{k-1} F\left[T_{i}\right] .
$$

Proof. Let $x$ be any point in $\bigcap_{i=1}^{k-1} F\left[T_{i}\right]$. We see that $T_{k} x=$ $T_{k} T_{i} x=T_{i} T_{k} x$ for all $i$ such that $1 \leqq i \leqq k-1$, which implies that $T_{k} x$ belongs to $F\left[T_{i}\right]$ for all $1 \leqq i \leqq k-1$.

Proof of theorem. For all $i$ such that $1 \leqq i \leqq \nu$, put

$$
\left[\prod_{n_{i-1}=1}^{n_{i}}\left[S_{i} \prod_{n_{i-2}=1}^{n_{i-1}}\left[S_{i-1} \cdots\left[S_{2} \prod_{n_{0}=1}^{n_{1}} S_{1}\right] \cdots\right]\right]\right] x=P_{n_{i}}^{(i)} x
$$


We shall prove the theorem by induction. Let us assume that the following conditions are true for some integer $j$ such that $1 \leqq$ $j \leqq \nu-1$ :

(31) $P^{(j)}(D)=F\left[P^{(j)}\right]=\bigcap_{i=1}^{j} F\left[T_{i}\right] \subset F\left[P_{n_{j}}^{(j)}\right]$ for all integers $n_{j} \geqq 1$,

$$
\left\{P_{n_{j}}^{(j)}\right\}_{n_{j}=1}^{\infty} \text { converges uniformly to } P^{(j)}
$$

and

$$
T\left(P^{(j)}(D)\right) \subset P^{(j)}(D) .
$$

Since $P_{n_{j+1}}^{(j+1)} x=\left[\prod_{n_{j=1}}^{n_{j+1}}\left(S_{j_{+1}} P_{n_{j}}^{(j)}\right)\right] x$, we can apply Lemma 3 by regarding $T_{j+1}, S_{j+1}, P^{(j)}, P_{n_{j}}^{(j)}, P_{n_{j+1}}^{(j+1)}, P^{(j+1)}$ and conditions (30)-(33) as $T, S, P, P_{n}, P_{n}, P$ and conditions (19)-(22). Hence we have,

$$
\text { for any } x \text { in } D, \lim _{n_{j+1} \rightarrow \infty} P_{n_{j+1}}^{(j+1)} x=P^{(j+1)} x \text { exists , }
$$

$$
P^{(j+1)}(D)=F\left[P^{(j+1)}\right]=\bigcap_{i=1}^{j+1} F\left[T_{i}\right] \subset F\left[P_{j+1}^{(j+1)}\right] \text { for all } n_{j+1} \geqq 1
$$

and

$$
\left\{P_{n_{j+1}}^{(j+1)}\right\}_{n_{j+1}=1}^{\infty} \text { converges uniformly to } P^{(j+1)} \text {. }
$$

Moreover, if $j+2 \leqq \nu$, Lemma 4 shows from (35) that

$$
T_{j+1}\left(P^{(j+1)}\right)(D) \subset P^{(j+1)}(D) .
$$

When $j=1$, conditions (30)-(32) immediately follow by regarding $P$ in Lemma 2 as an identity mapping. Also from (31) and Lemma 4, we get (33).

Therefore, by induction, it follows that $\lim _{n_{\nu} \rightarrow \infty} P_{n_{\nu}}^{(\nu)} x=P^{(\nu)} x \in$ $P^{(\nu)}(D)=\bigcap_{i=1}^{\nu} F\left[T_{i}\right]$. This completes the proof of the theorem.

From the finite intersection property, we have the following result due to DeMarr [2]. And note that we do not assume Zorn's lemma in our proof.

Corollary 1. Let $T_{i}(i \in J, J$ is an index set) be commuting nonexpansive mapping from a compact convex subset of a Banach space into itself. Then there exists a point $u$ in $D$ such that $T_{i} u=u$ for all $i \in J$.

When $\nu=1$ and $\alpha_{1}=1 / 2$, we have the following corollary, which is essentially equal to the result we have obtained as a Corollary 2 in [3]. 
CoROLlaRY 2. Let $T$ be a nonexpansive mapping from a compact convex subset $D$ of a Banach space into itself. Then $\left\{((I+T) / 2)^{n} x\right\}_{n=1}^{\infty}$ converges to a fixed point of $T$.

The author would like to thank the referee for letting me know about reference [5].

\section{REFERENCES}

1. L. P. Belluce and W. A. Kink, Fixed point theorems for families of contraction mappings, Pacific J. Math., 18 (1966), 213-217.

2. R. E. DeMarr, Common fixed-points for commuting contraction mappings, Pacific J. Math., 13 (1963), 1139-1141.

3. S. Ishikawa, Fixed points and iteration of a nonexpansive mapping in a Banach space, Proc. Amer. Math. Soc., 59 (1976), 65-71.

4. T. C. Lim, A fixed point theorem for families of nonexpansive mappings, Pacific J. Math., 53 (1974), 487-493.

5. J. Linhart, Beiträge zur Fixpunkttheorie nichtexpandierender Operatoren, Monatshefte für Mathematik, 76 (1972), 239-249.

Received May 30, 1978.

Faculty of Engineering Keio University

832 Hiyoshi-CHo, КоHоKU-KU

YOKOHAMA 223, JAPAN 



\section{PACIFIC JOURNAL OF MATHEMATICS}

\section{EDITORS}

RICHARD ARENS (Managing Editor)

University of California

Los Angeles, CA 90024

Charles W. Curtis

University of Oregon

Eugene, OR 97403

C. C. MOORE

University of California

Berkeley, CA 94720
J. DUGUNDJI

Department of Mathematics

University of Southern California

Los Angeles, CA 90007

R. FINN and J. MILGRAM

Stanford University

Stanford, CA 94305

\section{ASSOCIATE EDITORS}

\section{E. F. BeCKENBACH}

B. H. NeumanN

F. WOLF

K. YoSHIDA

\section{SUPPORTING INSTITUTIONS}

\author{
UNIVERSITY OF SOUTHERN CALIFORNIA \\ STANFORD UNIVERSITY \\ UNIVERSITY OF HAWAII \\ UNIVERSITY OF TOKYO \\ UNIVERSITY OF UTAH \\ WASHINGTON STATE UNIVERSITY \\ UNIVERSITY OF WASHINGTON
}

The Supporting Institutions listed above contribute to the cost of publication of this Journal, but they are not owners or publishers and have no responsibility for its content or policies.

Mathematical papers intended for publication in the Pacific Journal of Mathematics should be in typed form or offset-reproduced, (not dittoed), double spaced with large margins. Please do not use built up fractions in the text of the manuscript. However, you may use them in the displayed equations. Underline Greek letters in red, German in green, and script in blue. The first paragraph or two must be capable of being used separately as a synopsis of the entire paper. Items of the bibliography should not be cited there unless absolutely necessary, in which case they must be identified by author and journal, rather than by item number. Manuscripts, in triplicate, may be sent to any one of the editors. Please classify according to the scheme of Math. Reviews, Index to Vol. 39. All other communications should be addressed to the managing editor, or Elaine Barth, University of California, Los Angeles, California, 90024.

50 reprints to each author are provided free for each article, only if page charges have been substantially paid. Additional copies may be obtained at cost in multiples of 50 .

The Pacific Journal of Mathematics is issued monthly as of January 1966. Regular subscription rate: $\$ 72.00$ a year (6 Vols., 12 issues). Special rate: $\$ 36.00$ a year to individual members of supporting institutions.

Subscriptions, orders for numbers issued in the last three calendar years, and changes of address should be sent to Pacific Journal of Mathematics, P.O. Box 969, Carmel Valley, CA 93924, U.S.A. Older back numbers obtainable from Kraus Periodicals Co., Route 100, Millwood, NY 10546.

PUBLISHED BY PACIFIC JOURNAL OF MATHEMATICS, A NON-PROFIT CORPORATION

Printed at Kokusai Bunken Insatsusha (International Academic Printing Co., Ltd.). 8-8, 3-chome, Takadanobaba, Shinjuku-ku, Tokyo 160, Japan. 


\section{Pacific Journal of Mathematics}

\section{Vol. 80, No. $2 \quad$ October, 1979}

K. Adachi, On the multiplicative Cousin problems for $N^{p}(D) \ldots \ldots \ldots \ldots 297$

Howard Banilower, Isomorphisms and simultaneous extensions in $C(S) \ldots 305$

B. R. Bhonsle and R. A. Prabhu, An inversion formula for a distributional

finite-Hankel-Laplace transformation ................... 313

Douglas S. Bridges, Connectivity properties of metric spaces.......... 325

John Patton Burgess, A selection theorem for group actions ........... 333

Carl Claudius Cowen, Commutants and the operator equations

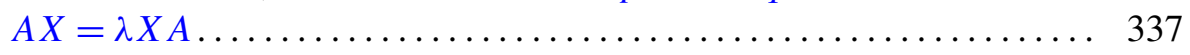

Thomas Curtis Craven, Characterizing reduced Witt rings. II .......... 341

J. Csima, Embedding partial idempotent d-ary quasigroups ............ 351

Sheldon Davis, A cushioning-type weak covering property ............ 359

Micheal Neal Dyer, Nonminimal roots in homotopy trees ............. 371

John Erik Fornaess, Plurisubharmonic defining functions ........... 381

John Fuelberth and James J. Kuzmanovich, On the structure of finitely

generated splitting rings .......................... 389

Irving Leonard Glicksberg, Boundary continuity of some holomorphic

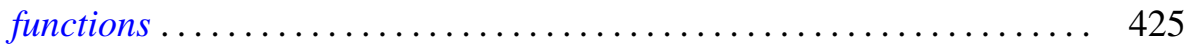

Frank Harary and Robert William Robinson, Generalized Ramsey theory.

IX. Isomorphic factorizations. IV. Isomorphic Ramsey numbers .......

Frank Harary and Allen John Carl Schwenk, The spectral approach to determining the number of walks in a graph...........

David Kent Harrison, Double coset and orbit spaces ..... . .

Shiro Ishikawa, Common fixed points and iteration of commuting

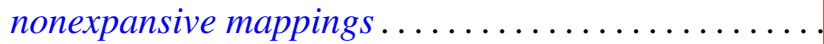

Philip G. Laird, On characterizations of exponential polynomials ........ 503

Y. C. Lee, A Witt's theorem for unimodular lattices ...........

Teck Cheong Lim, On common fixed point sets of commutative

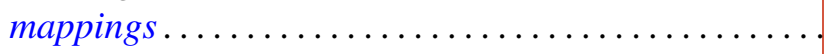

R. S. Pathak, On the Meijer transform of generalized functions ...

T. S. Ravisankar and U. S. Shukla, Structure of $\Gamma$-rings . . .

Olaf von Grudzinski, Examples of solvable and nonsolvable convolution

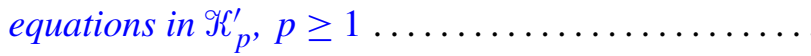

